\title{
Polymer Structure of Lignophenol I —Structure and Function of Fractionated Lignophenol-
}

\author{
Keigo Mikame and Masamitsu FunAOKA ${ }^{\dagger}$ \\ Faculty of Bioresources, Mie University, 1577 Kurima-machiya, Tsu 514-8507, Japan \\ (Received September 26, 2005; Accepted February 11, 2006; Published May 19, 2006)
}

\begin{abstract}
A polymer structure and function of lignophenol was examined by various structural analysis of lignophenols fractionated with preparative SEC. The base unit of lignophenol is 1,1-bis (aryl) propane-2-O-aryl ether unit in all the molecular weight areas by NMR analysis. But the amounts of combined cresol and phenolic hydroxyl groups were increased with decreasing molecular weight of fractionated lignophenols. The protein-adsorbing capacities and thermoplastic property of fractionated lignophenols differed with the molecular weights. [doi:10.1295/polymj.PJ2005142]

KEY WORDS Lignin / Fractionation / Molecular Weight / Polymer Structure / Phase-separation System / Lignophenol /
\end{abstract}

Lignin is the most abundant natural polymer next to cellulose and exists in plant cell walls as one of the major constituents. However, in contrast to the importance and potential of lignin in nature, lignin-based products have scarcely been in human life. This strange phenomenon is due to complicated structure and reactivity of lignin. Lignin is biosynthesized via random radical coupling of $p$-hydroxycinnamyl alcohols, which is initiated by enzymatic one-electron oxidation of phenolic hydroxyl groups. ${ }^{1,2}$ Thus lignin has a variety of inter-unit linkage and an amorphous three-dimensional network polymer. ${ }^{3,4}$ Furthermore, complicated modifications of the lignin structure are caused through isolation process from the cell wall. Presently kraft lignin which is the most abundant commercial lignin can be produced mainly as byproducts in kraft pulping process. However the lignin from kraft pulping process are burned for the production of energy for pulping process, so they are not utilized as raw materials for chemicals. In order to utilize the kraft lignin as more valuable materials, the conversion of kraft lignin to functional polymers has been attempted by many researchers, ${ }^{5-8}$ but any industrial use of the lignin has not been accomplished. Therefore it is difficult to change highly modified lignin into functional polymers.

Recently lignin-based functional polymer (lignophenols) has originally been designed and their synthesis process from native lignin (original lignin in wood) has been developed. ${ }^{9}$ This process includes the phase-separation reaction system composed of phenol derivatives and concentrated acid. In the process, native lignin was modified by selectively grafting phenol derivatives to benzyl position, the most reac- tive sites, to give lignophenols that remain the original interunit linkage of lignin and have high phenolic content (Scheme 1).

The lignophenols have several unique functions, for example lignophenols indicate an apparent solidliquid transformation at $c a .130^{\circ} \mathrm{C}$ in hardwood and at $c a .170^{\circ} \mathrm{C}$ in softwood, and high immobilization capability for proteins (enzyme). ${ }^{10,11}$

In this study, the correlation between these unique functions of lignophenols and polymer structures were investigated.

\section{EXPERIMENTAL}

\section{Wood and Lignin Preparations}

Air-dried wood samples were ground to pass an 80 mesh screen and extracted with ethanol-benzene (1:2, $\mathrm{v} / \mathrm{v})$ for $48 \mathrm{~h}$ to remove extractives. Milled wood lignin (MWL) was prepared from extractive free Yezo spruce (Picea jezoensis) and Japanese birch (Betula platyphylla) wood meals, according to Björkman. ${ }^{12}$

\section{Preparation of Lignocresol}

For solvation of lignin with phenol derivatives, $3 \mathrm{~mol} / \mathrm{C} 9$ (phenyl propane unit of lignin) of $p$-cresol dissolved in acetone was added to wood meal and acetone was evaporated with stirring. Sulfuric acid (72\% $10 \mathrm{~mL} / \mathrm{g}$ wood) was added to the mixture and the vigorous stirring was continued at $30^{\circ} \mathrm{C}$ for $60 \mathrm{~min}$. The reaction mixture was rapidly poured to excess distilled water. The insoluble fraction was collected by centrifugation, washed with distilled water until neutral and lyophilized. The dried insoluble fraction was extracted with acetone. The acetone solution was then concen-

${ }^{\dagger}$ To whom correspondence should be addressed (Tel: +81-59-231-9521, Fax: +81-59-231-9521, E-mail: funaoka@ bio.mie-u.ac.jp). 


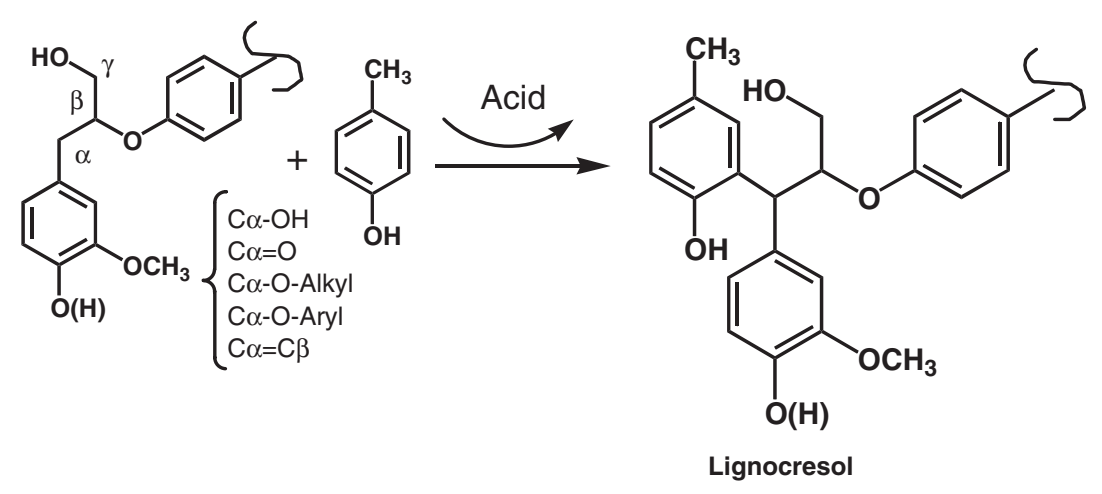

Scheme 1. A schematic model of phase separation system.

trated under reduced pressure and added dropwise to an excess amount of diethyl ether with stirring. The precipitated lignin derivative (lignocresol) was collected by centrifugation. Yields of lignocresol from spruce and birch were $27.5 \%$ of wood and $22.2 \%$ of wood respectively.

\section{Fractionation of Lignocresol}

Lignocresol was fractionated by preparative size exclusion chromatography (SEC) on Shimadzu LC-8A recycle preparative system equipped with Shimadzu SPD-10AUV/VIS detector. Shodex GPC KF-5002.5 $(50 \mathrm{~mm} \mathrm{ID} \times 300 \mathrm{~mm})$ was connected and tetrahydrofuran (THF) used as an eluent [flow rate; $10 \mathrm{~mL} / \mathrm{min}$ ].

The fractionated lignocresols solutions were evaporated to dryness under reduced pressure and dissolved in acetone. The acetone solutions were added dropwise to an excess amount of $n$-hexane with stirring. The precipitates were collected by centrifugation.

\section{Molecular Weight Distribution of Fractionated Lignocresols}

Size exclusion chromatogram of lignocresol was determined on a JASCO PU-1580 High-Performance Liquid Chromatograph (HPLC) equipped with JASCO MD-1515 multi wavelength detector. Shodex GPC KF-801,802,803,804 (8 mm ID × $300 \mathrm{~mm})$ was connected in series and tetrahydrofuran (THF) used as an eluent [flow rate; $1.0 \mathrm{~mL} / \mathrm{min}$ ]. Calibration for weight-average molecular weight $\left(M_{\mathrm{w}}\right)$, number-average molecular weight $\left(M_{\mathrm{n}}\right)$ and polydispercity $\left(M_{\mathrm{w}} /\right.$ $M_{\mathrm{n}}$ ) was performed using standard polystyrene.

\section{Contents of Combined Cresol and Hydroxyl Groups of Fractionated Lignocresols}

${ }^{1} \mathrm{H}$ NMR analyses of fractionated lignocresols were performed on a JEOL JNM-A500 FT-NMR System. The amount of cresol induced was calculated based on the signal intensity of cresolic methyl protons (1.6-2.4 ppm) against aromatic protons (7.8-8.4 ppm) of $p$-nitrobenzaldehyde (internal standard) on ${ }^{1} \mathrm{H}$ NMR spectra. ${ }^{10}$ The hydroxyl group contents were determined from phenolic acetoxyl proton signals $(2.0-2.4 \mathrm{ppm})$ and aliphatic acetoxyl proton signals (1.6-2.0 ppm) on ${ }^{1} \mathrm{H}$ NMR spectra of acetylatated lignocresols. The cresolic methyl proton signals overlapped in the region of acetoxyl protons were estimated based on the relative intensity of cresolic methylto aromatic proton signals (6.3-7.8 ppm) in the spectra of original lignocresols. ${ }^{10}$

\section{${ }^{13}$ C NMR Analysis of Fractionated Lignocresols}

${ }^{13} \mathrm{C}$ NMR analyses of fractionated lignocresols were performed on a JEOL JNM-A500 FT-NMR System. About $50 \mathrm{mg}$ of a fractionated lignocresol was dissolved in hexadeuterioacetone. The number of acquisition was about 20000 .

\section{FT-IR of Spectra of Fractionated Lignocresols}

FT-IR spectra of fractionated lignocresols were determined on Perkin Elmer Spectrum GX FT-IR Spectroscopy using $\mathrm{KBr}$ discs. The spectra were recorded from 400 to $4000 \mathrm{~cm}^{-1}$.

\section{UV-Vis of Spectra of Fractionated Lignocresols}

Ultraviolet and Visible spectra of fractionated lignocresols were determined continuously in the wavelength region of $600-200 \mathrm{~nm}$ on a JASCO V-560 spectrometer. Methyl cellosolve was used as solvents.

\section{Thermomechanical Analysis (TMA) of Fractionated Lignocresols}

Thermomechanical analyses of fractionated lignocresols were performed on a SEIKO EXSTAR 6000 TMA/SS. About $5 \mathrm{mg}$ of a powdered sample was placed in an aluminum pan $(5 \mathrm{~mm} \phi \times 2 \mathrm{~mm})$ and aluminum plate $(2 \mathrm{~mm} \times 2 \mathrm{~mm})$ was put on the sample. The sample was compressed with the quartz probe with a $5 \mathrm{~g}$ load under a nitrogen stream and heating rate was carried on $2{ }^{\circ} \mathrm{C} / \mathrm{min} .{ }^{13}$ 
Determination of the Protein-adsorbing Capacities of Fractionated Lignocresols

Lignocresols $(10 \mathrm{mg})$ were suspended in $1 \mathrm{~mL}$ of $200 \mathrm{mM}$ acetate buffer solution ( $\mathrm{pH} 4.5)$. An $1 \mathrm{~mL}$ of bovine serum albumin (BSA) solutions $(2 \mathrm{mg} / \mathrm{mL})$ was added to the suspension, and stirred at $20^{\circ} \mathrm{C}$ for $1 \mathrm{hr}$. The resulting lignin-protein complex were centrifuged and filtrated, and then free BSA in the supernatant solution was determined by the Bradford method. ${ }^{14}$ Adsorbed BSA was calculated by subtracting the BSA in the supernatant solution from the BSA added.

\section{RESULTS AND DISCUSSION}

\section{Fractionation of Lignocresol}

Lignocresols from Yezo spruce (Picea jezoensis) and Japanese birch (Betula platyphylla) were fractionated to five fractions by recycle preparative SEC. Weight average molecular weight $\left(M_{\mathrm{w}}\right)$ of original spruce lignocresol was $12900 \quad\left(M_{\mathrm{w}} / M_{\mathrm{n}}=2.57\right)$. Weight average molecular weight of highest molecular weight fraction (Fr-1) was $66700\left(M_{\mathrm{w}} / M_{\mathrm{n}}=3.08\right)$. Weight average molecular weight of main fraction (Fr-3) was $9600\left(M_{\mathrm{w}} / M_{\mathrm{n}}=1.21\right)$. Weight average molecular weight of lowest molecular weight fraction $\left(\right.$ Fr-5) was $2600\left(M_{\mathrm{w}} / M_{\mathrm{n}}=1.20\right)$ (Table I). $M_{\mathrm{w}}$ of fractionated birch lignocresols was lower than fractionated lignocresols from spruce (Table I).

\section{Contents of Combined Cresol and Hydroxyl Groups of Fractionated Lignocresols}

The contents of hydroxyl groups and cresol groups in the lignocresol molecular from spruce and birch are in Table II, III respectively. The contents of hydroxyl groups and cresol groups in fractionated birch lignocresols were slightly higher than fractionated spruce lignocresols. The amounts of aliphatic hydroxyl group did not have a large difference between each fraction

Table I. Yields and molecular weights of fractionated lignocresols

\begin{tabular}{lrrc}
\hline & Yields & $M_{\mathrm{w}}$ & $M_{\mathrm{w}} / M_{\mathrm{n}}$ \\
\hline Fr-1 & 10.5 & 66714 & 2.57 \\
Fr-2 & 18.8 & 28513 & 1.62 \\
Fr-3 & 36.3 & 9592 & 1.21 \\
Fr-4 & 25.2 & 4034 & 1.34 \\
Fr-5 & 9.1 & 2556 & 1.20 \\
Spruce Lignocresol & 12922 & 3.08 \\
Fr-1 & 9.6 & 47253 & 3.34 \\
Fr-2 & 24.9 & 13141 & 1.42 \\
Fr-3 & 35.9 & 5536 & 1.20 \\
Fr-4 & 19.1 & 2938 & 1.14 \\
Fr-5 & 10.5 & 2265 & 1.53 \\
Birch Lignocresol & & 8196 & 2.16 \\
\hline
\end{tabular}

Table II. Hydroxyl groups and cresol contents of fractionated spruce lignocresol

\begin{tabular}{lcccccl}
\hline & Fr-1 & Fr-2 & Fr-3 & Fr-4 & Fr-5 & Lignocresol \\
\hline Phenolic & 0.78 & 1.17 & 1.14 & 1.19 & 1.28 & 1.21 \\
Aliphatic & 1.00 & 1.08 & 1.09 & 1.09 & 0.98 & 1.13 \\
Total & 1.78 & 2.25 & 2.23 & 2.28 & 2.26 & 2.34 \\
Combined cresol & 0.46 & 0.60 & 0.71 & 0.73 & 0.78 & $0.70(\mathrm{~mol} / \mathrm{C} 9)$ \\
\hline
\end{tabular}

Table III. Hydroxyl groups and cresol contents of fractionated birch lignocresol

\begin{tabular}{lcccccl}
\hline & Fr-1 & Fr-2 & Fr-3 & Fr-4 & Fr-5 & Lignocresol \\
\hline Phenolic & 1.09 & 1.14 & 1.25 & 1.44 & 1.51 & 1.47 \\
Aliphatic & 0.87 & 1.05 & 0.89 & 1.25 & 0.84 & 1.00 \\
Total & 1.96 & 2.19 & 2.05 & 2.69 & 2.35 & 2.47 \\
Combined cresol & 0.70 & 0.78 & 0.86 & 0.87 & 0.92 & 0.89 (mol/C9) \\
\hline
\end{tabular}

of fractionated lignocresols. However the amounts of combined cresol of high molecular weight fraction (Fr-1) were lower than low molecular weight fraction (Fr-5). The amounts of phenolic hydroxyl groups were also increased with decreasing molecular weight of fractionated lignocresol. The difference between the amount of total phenolic hydroxyl groups and the amount of combined cresol shows the amount of phenolic hydroxyl group of original lignin moiety. Therefore the amount of phenolic hydroxyl group originated from native lignin in low molecular weight fraction is more than that of high molecular weight fraction. In the phase separation system, phenol derivatives were grafted at benzyl position selectively following the cleavage of aryl ether bond or elimination of hydroxyl group at benzyl position. ${ }^{9}$ Thus it is thought that lignocresol of the low molecular weight fraction was derived from native lignin having many hydroxyl group or aryl ether bond, not carbon-carbon bond at benzyl position.

\section{${ }^{13}$ C NMR Analysis of Fractionated Lignocresols}

In the ${ }^{13} \mathrm{C}$ NMR analysis, the number of signals of lignocresol from spruce was fewer than MWL from spruce (Figure 1). The signals of side chain aliphatic carbon $(45,62$ and $84 \mathrm{ppm})$ and aromatic carbon (110-150 ppm) of lignocresol were extremely simpler, compared with MWL. Although the signal of carbonyl carbon (190-200 ppm) existed in spruce MWL, spruce lignocresol dose not have carbonyl groups. This means that the complex native lignin was converted into simple structures through the phase separation treatment. ${ }^{9}$ This result suggests that the base unit of lignocresol is 1,1-bis (aryl) propane-2-O-aryl ether unit in all the molecular weight areas.

In original lignocresols, aromatic carbon signals $(116,130$ and $153 \mathrm{ppm})$ of grafted $p$-cresol were sharper, compared with aromatic carbon signals 

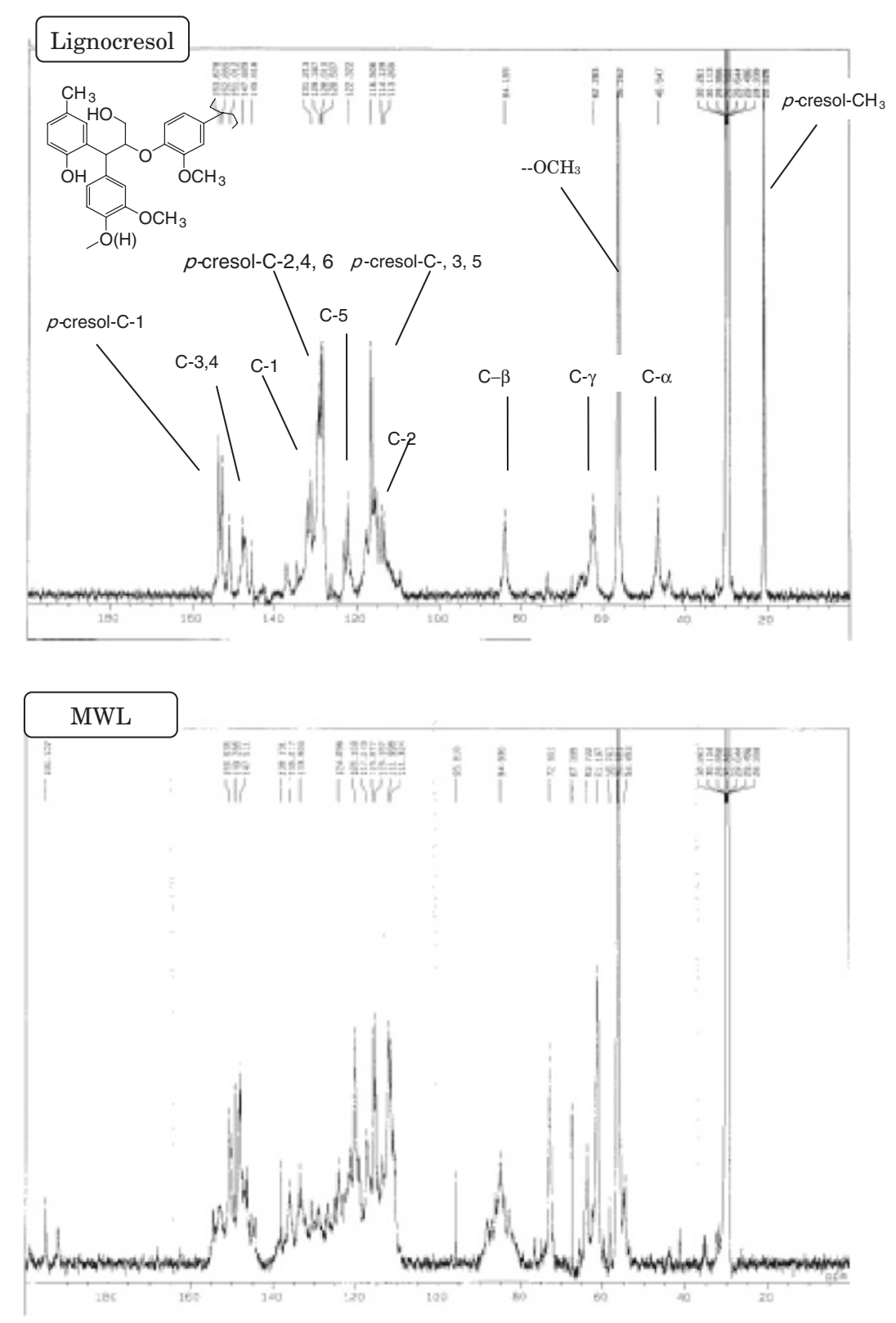

Figure 1. ${ }^{13} \mathrm{C}$ NMR spectra of spruce lignocresol and MWL.

$(113,122,145$ and $151 \mathrm{ppm})$ of original lignin moieties). In the fractionated lignocresol, the signal patterns of high and low molecular weight lignocresols and original lignocresol were similar (Figure 2).

\section{FT-IR and UV-Vis Spectra of Fractionated Lignocre- sols}

As shown in Figure 3, FT-IR spectra of original lignocresols and fractionated lignocresols from spruce had similar peak pattern, and the carbonyl absorption peak around $1720 \mathrm{~cm}^{-1}$ was not observed in the spectrum. However the carbonyl absorption peak was slightly appeared in birch original lignocresol, and the peak was strong in low molecular weight fraction (Fr-5).

UV-Vis spectra for original lignocresols and frac- tionated lignocresols from spruce and birch were shown in Figure 4. The UV-Vis spectra of original and fractionated lignocresols from spruce had a sharp band only at $280 \mathrm{~nm}$, and hardly shoulder or band at longer wavelengths which exist in MWL. ${ }^{15,16}$ These indicate selective and effective grafting of $p$-cresol at reactive sites in the side chains, leading to the disappearance of conjugated systems in the molecular. ${ }^{15}$ But the UV-Vis spectra of low molecular weight fraction (Fr-5) of birch lignocresol had slightly higher absorbance at wavelengths longer than $300 \mathrm{~nm}$, compared with high and middle molecular weight fractions. It was thought that this absorption was based on the carbonyl group showed on FT-IR spectrum and small amount of ester bond was contained in low molecular weight fraction. 

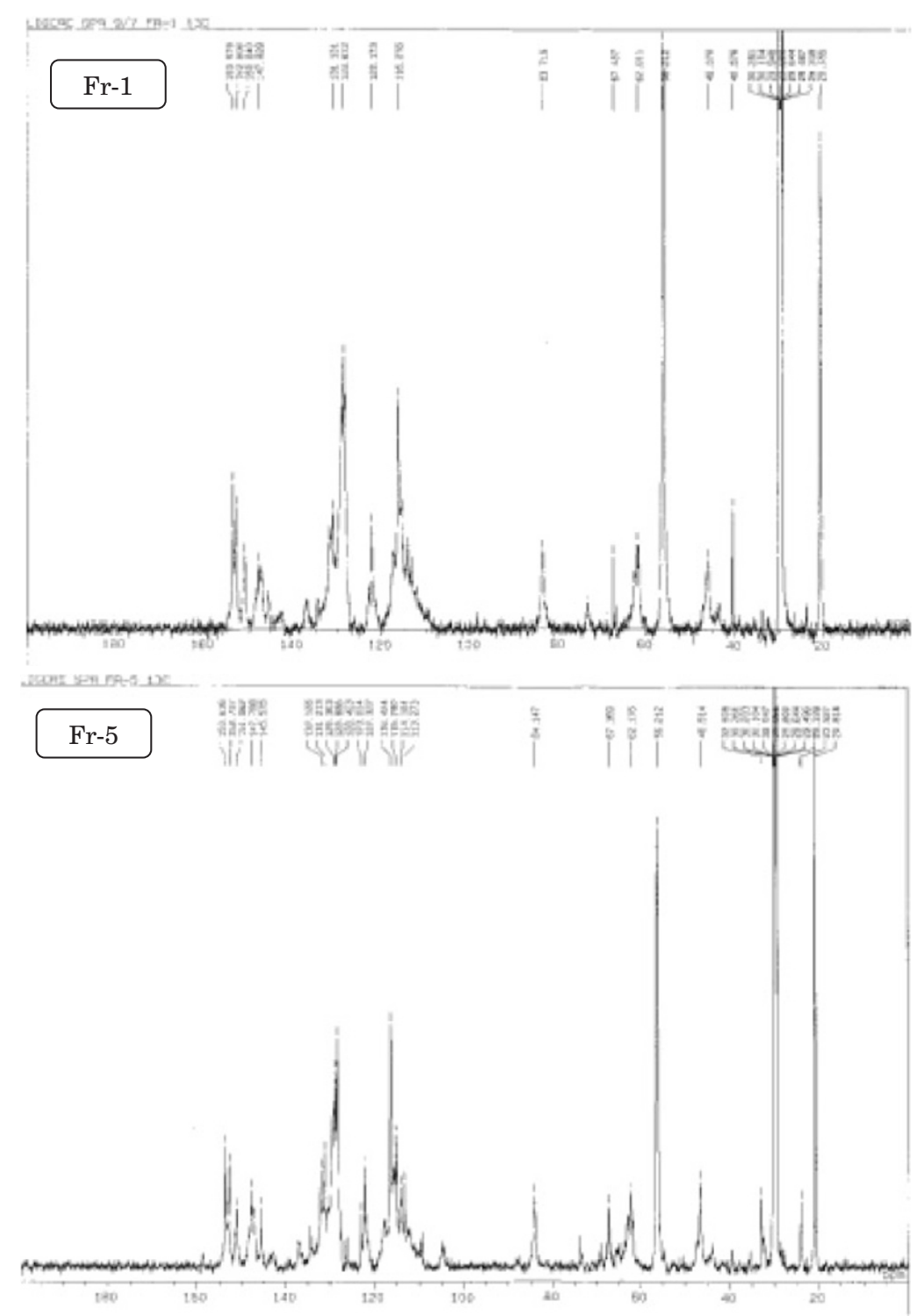

Figure 2. ${ }^{13} \mathrm{C}$ NMR spectra of fractionated spruce lignocresol.

\section{TMA Analysis of Fractionated Lignocresols}

The TMA curves of lignocresols from spruce and birch revealed volume decreasing at $160-180^{\circ} \mathrm{C}$ due to transformation of solid state to clear liquid state (Figure 5). ${ }^{13}$ On the other hand, MWL from spruce cannot be transformed into fluid liquid under this condition. Because native lignin, three dimentional network polymer, are convert to linear-type polymers with high frequency of 1,1-bis (aryl) propane-2-O-aryl ethers during the phase separation treatment. ${ }^{17}$ The phase-transition point of low molecular weight fraction (Fr-5) of lignocresol from spruce and birch was lower temperature (spruce: $155^{\circ} \mathrm{C}$, birch: $145^{\circ} \mathrm{C}$ ) than main fraction (Fr-3) of fractionated lignocresol. The relationship between the phase-transition point and molecular weight was consist with the thermal behavior of fractionated kraft lignin, as investgated by DSC. ${ }^{18}$ Original lignocresol and high molecular weight fraction (Fr-1) had lower phase-transition point than Fr-3, because original lignocresol and Fr-1 has wider molecular weight distribution than other fraction (Table I), and low molecular weight moieties act as plasticizer.

\section{Determination of the Protein-adsorbing Capacities of} Fractionated Lignocresols

Lignophenols show higher protein-adsorption capacities, compared with other lignin preparations. ${ }^{11}$ The affinity of lignocresol from spruce for BSA was 5-10 times higher than those of conventional lignins (kraft lignin, soda lignin, dioxane lignin etc.). ${ }^{11}$ In general, the phenolic hydroxyl group has been known to be very important for the protein affinity of phenolic polymers. ${ }^{19,20}$ However, the BSA affinity of high molecular weight fraction was higher than low molecular weight fraction with higher content of phenolic 


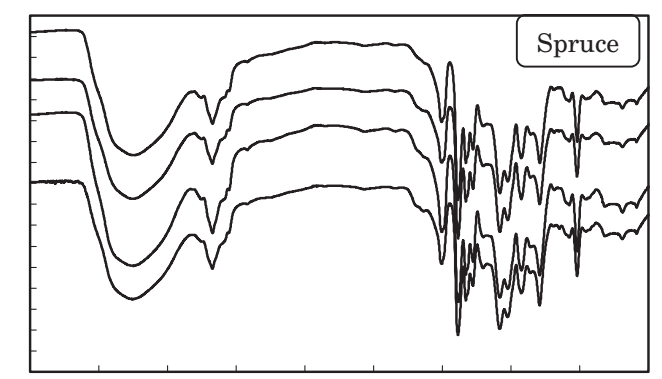

Lignocresol

Fr-1

Fr-3

Fr-5

$4000 \quad 3600 \quad 3200 \quad 2800 \quad 2400 \quad 2000 \quad 1600 \quad 1200 \quad 800 \quad 400 \quad c m$

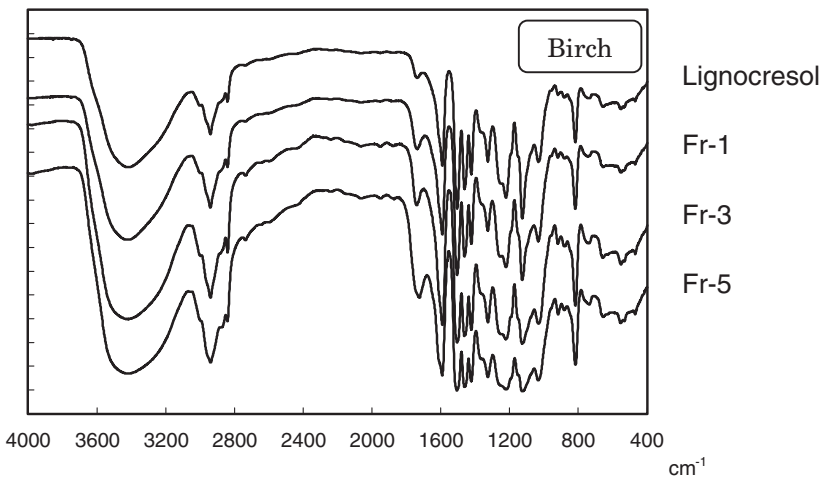

Figure 3. FT-IR spectra of fractionated lignocresol.
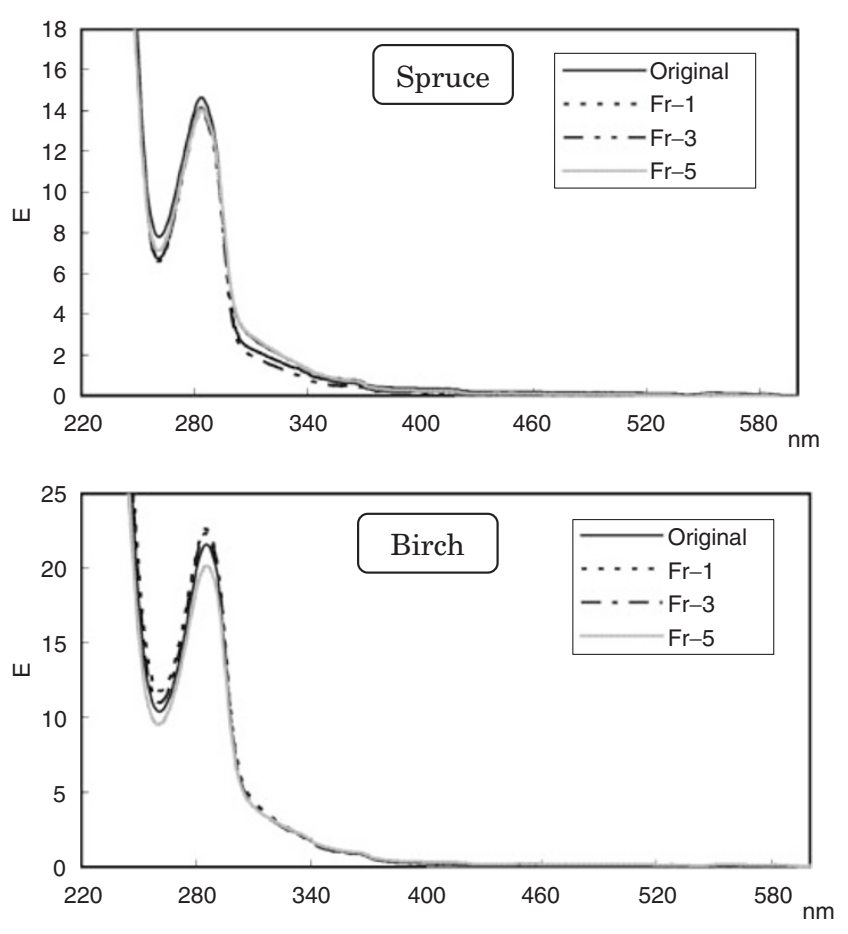

Figure 4. UV-Vis spectra of fractionated lignocresol.
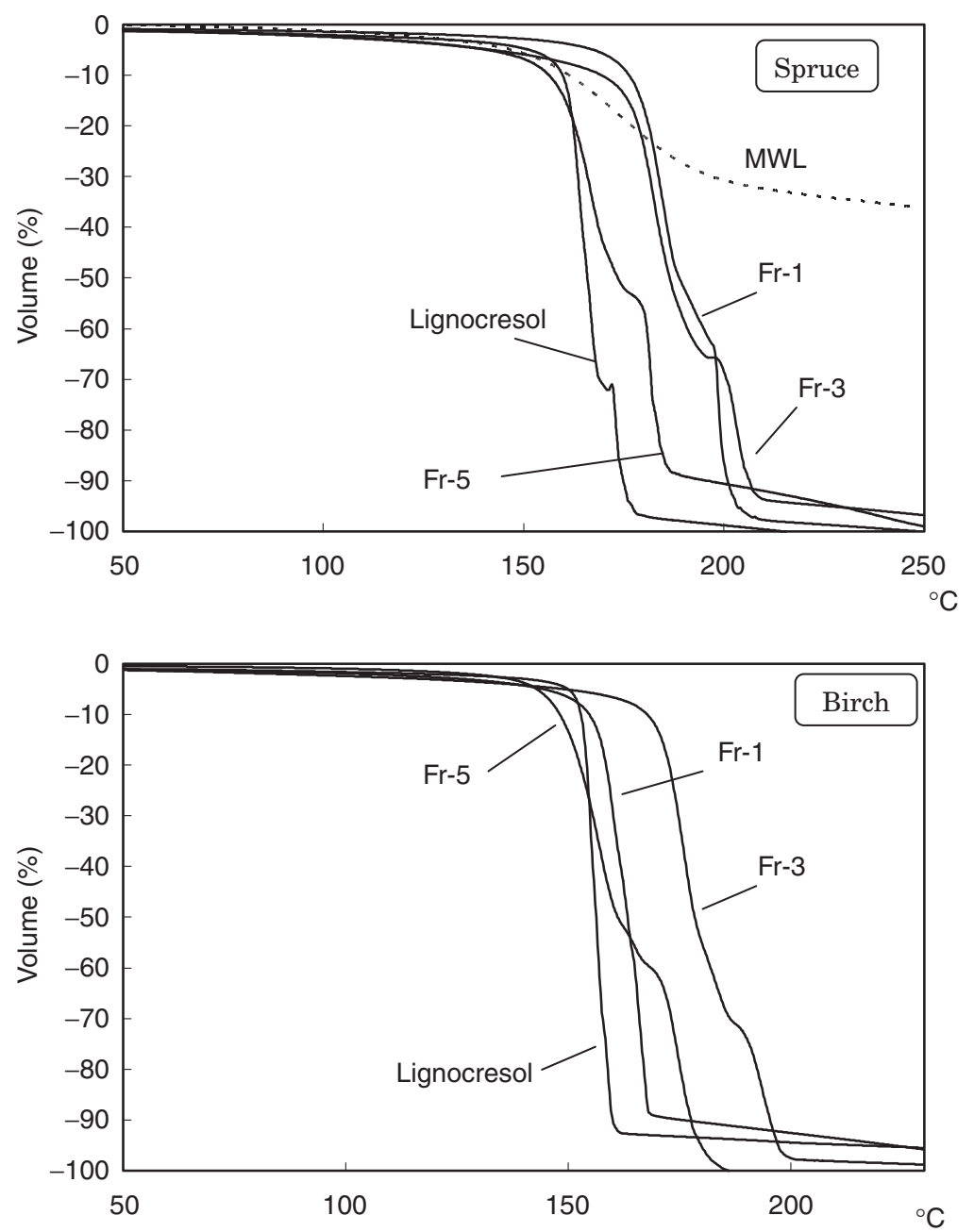

Figure 5. TMA curves of fractionated lignocresol from spruce and birch. 


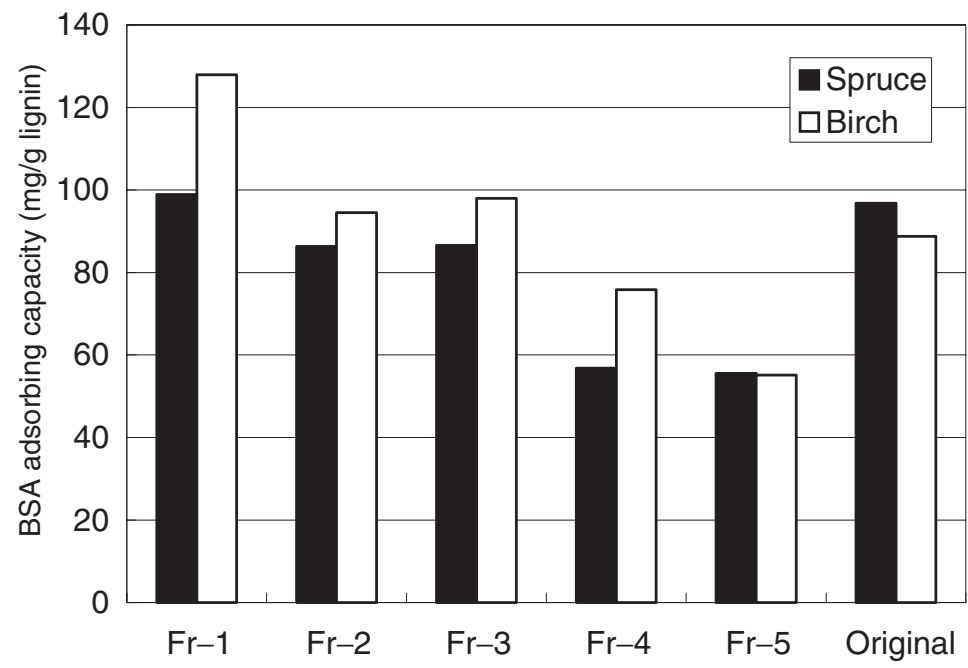

Figure 6. BSA affinities of fractionated lignocresol from spruce and birch.

hydroxyl group (Figure 6). The tendency was explained by the protein adsorption mechanism of lignophenols. In previous studies,${ }^{11}$ the maximum protein adsorption to lignophenol was achieved around the isoelectric points of the proteins used and the adsorbed protein did not desorb under acidic and basic condition, that is, the affinity between lignocresol and protein is not only due to the electric effect but also due to hydrophobic interaction between lignocresol and protein.

\section{CONCLUSIONS}

A polymer structure and function of lignophenol was examined by various structural analysis of lignocresols fractionated with preparative SEC. The base unit of lignocresol is 1,1-bis(aryl) propane unit in all the molecular weight areas by ${ }^{13} \mathrm{C}$ NMR analysis of fractionated lignicresol. But the amounts of combined cresol and phenolic hydroxyl groups were increased with decreasing molecular weight of fractionated lignocresols. The protein-adsorbing capacities and thermoplastic property of fractionated lignocresols differed with the molecular weights. The molecular weight control of lignophenol is achieved by preparation process of lignophenol from native lignin and alkaline treatment of lignophenol other than fractionation. ${ }^{21}$ Thus more effective use of lignophenol is possible through the control of molecular size of lignophenol.

\section{REFERENCES}

1. K. Freudenberg, Science, 148, 595 (1965).

2. T. Higuchi, J. Biochem., 45, 515 (1958).

3. D. A. Goring, in "Lignins: Occurrence, Formation, Structure and Reactions," K. V. Sarkanen and C. H. Ludwing, Ed., Willey-Interscience, New York, 1971.

4. K. Freudenberg, Holzforschung, 18, 3 (1964).

5. J. W. Adams and M. W. Schoenherr, U.S. Patent 4303562 (1981).

6. H. Nimz, "Wood Addhes. Chem. Technol.," A. Pizzi Ed., Ch.5, Dekker, New York, 1983, p 245.

7. M. R. Clark and J. D. Dolenko, U.S. Patent 4113675 (1978).

8. P. C. Muller, S. S. Kelly, and W. G. Glasser, J. Adhes., 17, 185 (1984).

9. M. Funaoka and I. Abe, Tappi J., 72, 145 (1989).

10. M. Funaoka and S. Fukatsu, Holzforschung, 50, 245 (1996).

11. M. Funaoka, Polym. Int., 47, 277 (1998).

12. A. Björkman, Svensk Papperstidning, 59, 477 (1956).

13. Y. Nagamatsu and M. Funaoka, Sen-i-Gakkaishi, 57, 75 (2001).

14. M. Bradford, Anal. Biochem., 26, 248 (1976).

15. M. Funaoka, M. Matsubara, N. Seki, and S. Fukatsu, Biotechnol. Bioeng., 46, 545 (1995).

16. G. A. Erdtman and R. Sanden, Acta Chem. Scand., 22, 1187 (1968).

17. M. Funaoka, Macromol. Symp., 201, 213 (2003).

18. H. Hatakeyama, K. Iwashita, G. Meshitsuka, and J. Nakano, Mokuzai Gakkaishi, 22, 618 (1975).

19. Y. Nakamoko and S. Ishida, Kobunshi Ronbunshu, 10, 151 (1984).

20. E. Haslam, Biochem. J., 139, 285 (1974).

21. M. Funaoka, H. Ioka, T. Hosho, and Y. Tanaka, J. Network polym. Jpn., 17, 121 (1996). 